\title{
Ractopamina em dietas sem ajustes aminoacídicos para suínos machos castrados em terminação ${ }^{1}$
}

\author{
Danilo Alves Marçal ${ }^{2}$, Charles Kiefer*3, Karina Márcia Ribeiro de Souza ${ }^{4}$, Rodrigo Caetano de Abreu ${ }^{5}$, \\ Rafael Arantes Rosa ${ }^{6}$, Lorena Silva da Rosa \\ http://dx.doi.org/10.1590/0034-737X201562030005
}

\begin{abstract}
RESUMO
Este estudo teve o objetivo de avaliar planos de suplementação com ractopamina, em dietas sem ajustes aminoacídicos, para suínos machos castrados, em terminação. Foram utilizados 72 suínos machos castrados, com peso inicial de $68,61 \pm 3,89 \mathrm{~kg}$, distribuídos em seis planos de suplementação com duração de 30 dias (0 ppm; 5 ppm; 10 ppm; 20 ppm; 5 ppm, durante 15 dias, seguidos por $10 \mathrm{ppm}$ durante 15 dias; e $10 \mathrm{ppm}$ durante 15 dias seguidos por $20 \mathrm{ppm}$ durante 15 dias), com seis repetições e dois animais por unidade experimental. A suplementação com ractopamina melhorou a conversão alimentar. A suplementação com 5 ppm de ractopamina aumentou o ganho de peso diário. Os níveis de 10 e 20 ppm e as suplementações graduais reduziram o consumo de ração diário e de nutrientes. Não houve influência da suplementação sobre o peso de carcaça quente e o comprimento de carcaça. A ractopamina reduziu a espessura de toucinho e aumentou a profundidade de músculo, o percentual de carne magra, a quantidade de carne magra e o índice de bonificação das carcaças. A suplementação de 5 ppm de ractopamina em dietas sem ajustes aminoacídicos melhora o desempenho e as características de carcaça de suínos em terminação, nos 30 dias pré-abate.
\end{abstract}

Palavras-chave: aditivo, Agonista $\beta$-adrenérgico, carcaça, desempenho, nutrição.

\section{ABSTRACT}

\section{Ractopamine in diets without amino acid adjustment for finishing barrows}

This study was conducted to evaluate ractopamine supplementation in diets without amino acid adjustment for finishing barrows. A total of 72 barrows with an initial weight of $68.61 \pm 3.89 \mathrm{~kg}$ were separated into six ractopamine supplementation plans during 30 days before slaughter ( 0 ppm, 5 ppm, 10 ppm, 20 ppm, 5 ppm for 15 days followed by $10 \mathrm{ppm}$ for 15 days, and $10 \mathrm{ppm}$ for 15 days followed by $20 \mathrm{ppm}$ for 15 days), with six replicates and two animals per experimental unit. Ractopamine supplementation improved feed conversion. Supplementation with 5 ppm ractopamine increased average daily gain. The levels of 10 and $20 \mathrm{ppm}$ and gradual supplementation reduced feed intake and nutrient intake. There was no effect of supplementation on hot carcass weight and carcass length. Ractopamine supplementation reduced backfat thickness and increased muscle depth, percentage of lean meat, amount of lean meat content and bonus carcass. The supplementation of diets with $5 \mathrm{ppm}$ of ractopamine without amino acid adjustments improved performance and carcass characteristics of finishing pigs 30 days before slaughter.

Key words: additive, Agonist $\beta$-Adrenergic, carcass, nutrition, performance.

\footnotetext{
Submetido em 17/05/2013 e aprovado em 12/05/2015.

1 Parte da dissertação de mestrado do primeiro autor.

${ }^{2}$ Universidade Federal de Mato Grosso do Sul, Programa de Pós-Graduação em Ciência Animal, Campo Grande, Mato Grosso do Sul, Brasil. danilomarcal@bol.com.br

${ }^{3}$ Universidade Federal de Mato Grosso do Sul, Faculdade de Medicina Veterinária e Zootecnia, Campo Grande, Mato Grosso do Sul, Brasil. charles.kiefer@ufms.br

${ }^{4}$ Universidade Federal de Mato Grosso do Sul, Faculdade de Medicina Veterinária e Zootecnia, Campo Grande, Mato Grosso do Sul, Brasil. karina.souza@ ufms.br

${ }^{5}$ Universidade Federal de Mato Grosso do Sul, Programa de Pós-Graduação em Ciência Animal, Campo Grande, Mato Grosso do Sul, Brasil. rodrigo.caetano_8@ @otmail.com

${ }^{6}$ Universidade Federal de Mato Grosso do Sul, Programa de Pós-Graduação em Ciência Animal, Campo Grande, Mato Grosso do Sul, Brasil. rafaelarantesrosa@ hotmail.com

${ }^{7}$ Universidade Federal de Mato Grosso do Sul, Programa de Pós-Graduação em Ciência Animal, Campo Grande, Mato Grosso do Sul, Brasil. lorenavetms@msn.com

*Autor para correspondência: charles.kiefer@ufms.br
} 


\section{INTRODUÇÃO}

A suplementação das dietas de suínos em terminação com ractopamina tem melhorado tanto o desempenho quanto as características de carcaça (See et al., 2004; Marinho et al., 2007; Main et al., 2009). Porém, sob ação contínua da ractopamina ocorre uma redução da resposta dos suínos ao estímulo provocado pelo aditivo (Mills, 2002), o aumento da quantidade de ractopamina fornecida durante o período de suplementação pode evitar essa redução das respostas (Armstrong et al., 2005).

Para atender a demanda adicional de proteína, decorrente do aumento do anabolismo proteico causado pela ractopamina, o nível aminoacídico da dieta deve ser reajustado. Por este motivo, vários pesquisadores (Marinho et al., 2007; Main et al., 2009; Almeida et al., 2010) adotam a recomendação de Xiao et al. (1999) de aumentar em $30 \%$ a quantidade de lisina em dietas suplementadas com ractopamina, independentemente da inclusão do aditivo. Entretanto, a resposta dos suínos ao aumento de lisina na dieta está relacionada com a inclusão de ractopamina (Webster et al., 2007).

Como o custo da utilização da ractopamina é elevado e, aliado à necessidade de reajuste da concentração aminoacídica, pode tornar sua utilização inviável na prática. Por esta razão, o objetivo deste estudo foi avaliar planos de suplementação com ractopamina, em dietas sem ajustes aminoacídicos para suínos machos castrados, em terminação.

\section{MATERIAL E MÉTODOS}

Este trabalho foi aprovado pela comissão de ética no uso de animais, sob protocolo $n^{\circ} 425 / 2012 /$ UFMS.

O experimento foi conduzido na Fazenda Experimental da Universidade Federal de Mato Grosso do Sul, em Terenos/MS. Foram utilizados 72 suínos, machos castrados, Pietran/Duroc x Large White/Landrace, com peso inicial de 68,61 $\pm 3,89 \mathrm{~kg}$, distribuídos em delineamento experimental de blocos ao acaso, composto por seis planos de suplementação com ractopamina ( 0 ppm; 5 ppm; 10 ppm; 20 ppm; 5 ppm durante 15 dias seguidos de 10 ppm durante 15 dias; e 10 ppm durante 15 dias seguidos de 20 ppm durante 15 dias), com duração de 30 dias e seis repetições. A unidade experimental foi composta por dois animais. Para a formação dos blocos, adotou-se o peso inicial dos animais como critério.

Durante o período experimental, a temperatura e a umidade relativa do ambiente foram monitoradas diariamente, por meio de um conjunto de termômetros de bulbo seco e bulbo úmido e de globo negro. Os valores registrados foram convertidos no índice de temperatura de globo e umidade (ITGU).
As dietas experimentais (Tabela 1) foram formuladas de modo a atender às exigências nutricionais estabelecidas por Rostagno et al. (2011) para suínos machos castrados, de alto potencial genético e desempenho superior. Os diferentes níveis de ractopamina foram obtidos a partir da inclusão de ractopamina em substituição ao caulim. Durante o período experimental, água e ração foram fornecidas à vontade aos animais.

A ração fornecida, as sobras dos comedouros e os resíduos coletados diariamente do chão foram pesados, para determinação do consumo diário de ração. As pesagens dos animais ocorreram no início e no final do experimento, para o cálculo do ganho de peso e da conversão alimentar. Os consumos de proteína bruta, lisina, energia metabolizável e ractopamina foram determinados, utilizando-se os valores de consumo de ração.

Ao final do período experimental, os animais foram encaminhados ao frigorífico e submetidos a jejum de sólidos por 12 horas, antes do abate. Ao final da linha de abate, as carcaças foram separadas em duas por um corte longitudinal na linha dorso-lombar, que corresponde à coluna vertebral, mensurando-se o seu comprimento da borda cranial da primeira costela até a borda cranial da sínfise pubiana, com fita métrica. Também foram medidos, no ponto $\mathrm{P} 2$, situado à altura da $10^{\mathrm{a}}$ costela, a espessura de toucinho e a profundidade do músculo Longissimus dorsi, com paquímetro digital.

O percentual de carne magra da carcaça foi determinado por meio da equação: rendimento de carne $(\%)=$ 60 - (espessura de toucinho $\times 0,58)+$ profundidade do músculo $\times 0,10$, proposta por Bridi \& Silva (2007). Para o cálculo do índice de bonificação de carcaça, foi utilizada a equação proposta por Guidoni (2000): índice de bonificação $=23,6+0,286 \times$ Peso de carcaça + Percentual de carne magra. A quantidade de carne magra da carcaça foi determinada por meio da multiplicação do percentual de carne magra pelo peso de carcaça.

Os dados obtidos foram submetidos à análise de variância, pelo procedimento GLM, do programa estatístico SAS. As eventuais diferenças das variáveis obtidas entre os níveis de ractopamina foram avaliadas pelo teste Student-Newman-Keuls (SNK), a 10\% de significância. As médias obtidas para os animais submetidos à dieta controle (isenta de ractopamina) foram comparadas às dos demais planos de suplementação com ractopamina, por meio do teste de Dunnett.

\section{RESULTADOS E DISCUSSÃO}

Durante o período experimental, os valores médios de temperatura ambiente, umidade relativa do ar, temperatura de globo negro e índice de temperatura de globo e umidade foram de $28,6 \pm 3,0{ }^{\circ} \mathrm{C}, 65,1 \pm 15,7 \%, 28,6 \pm$ $3,0{ }^{\circ} \mathrm{C}$ e $77,1 \pm 3,4$, respectivamente. Considerando-se 
que a temperatura média registrada foi superior à temperatura crítica máxima, de $27^{\circ} \mathrm{C}$, estabelecida para a categoria (Sampaio et al., 2004), pode-se inferir que os animais foram mantidos em ambiente de estresse moderado por calor.

Os animais alimentados com dietas suplementadas com 20 ppm de ractopamina apresentaram consumo de ração inferior $(\mathrm{P}<0,03)$ ao dos alimentados com a dieta controle e ao dos tratados com a dieta contendo 5 ppm de ractopamina (Tabela 2). Entretanto, quando se comparou o consumo dos suínos alimentados com as dietas suplementadas ao do grupo controle, constatouse que a suplementação com 10 e 20 ppm e as suplementações graduais reduziram $(\mathrm{P}<0,08)$ o consumo de ração. Este resultado está de acordo com as observações de Crome et al. (1996) que constataram redução do consumo de ração de suínos ao suplementarem as dietas com 10 e 20 ppm de ractopamina.

A suplementação com 20 ppm de ractopamina causou redução $(\mathrm{P}<0,03)$ do consumo de proteína bruta, lisina digestível e energia metabolizável, em relação ao consumo dos animais alimentados com a dieta controle e com a dieta suplementada com 5 ppm de ractopamina. Entretanto, ao se comparar o consumo de proteína bruta, lisina digestível e energia metabolizável do grupo controle ao dos demais grupos, verificou-se que as suplementações com 10 e 20 ppm e as suplementações graduais reduziram $(\mathrm{P}<0,08)$ o consumo desses nutrientes. Esse resultado está de acordo com a resposta observada para o consumo de ração, uma vez que as dietas experimentais utilizadas foram isonutritivas.

Os planos de suplementação com ractopamina não influenciaram $(\mathrm{P}>0,10)$ o ganho de peso diário. Contudo, comparando-se o ganho de peso de cada grupo que recebeu dietas suplementadas ao do grupo controle, constatou-se que a suplementação com 5 ppm de ractopamina aumentou $(\mathrm{P}<0,06)$ o ganho de peso diário. Esse resultado pode ser explicado pela redução do consumo de ração, provocado pelos demais planos de suplementação. Dessa forma, os animais apresentaram menor ingestão de proteína, energia e aminoácidos, conforme relatado anteriormente. Os resultados obtidos estão de acordo com os de Marinho et al. (2007), que observaram aumento do ganho de peso de suínos ma-

Tabela 1. Composição centesimal e nutricional das dietas experimentais para suínos em fase de terminação

\begin{tabular}{|c|c|c|c|c|}
\hline \multirow{2}{*}{ Ingredientes, kg } & \multicolumn{4}{|c|}{ Ractopamina (ppm) } \\
\hline & $\mathbf{0}$ & 5 & 10 & 20 \\
\hline Milho & 81,40 & 81,40 & 81,40 & 81,40 \\
\hline Farelo de Soja, $45 \%$ & 15,96 & 15,96 & 15,96 & 15,96 \\
\hline Óleo de soja & 0,020 & 0,020 & 0,020 & 0,020 \\
\hline Fosfato bicálcico & 0,899 & 0,899 & 0,899 & 0,899 \\
\hline Calcário calcítico & 0,608 & 0,608 & 0,608 & 0,608 \\
\hline Suplemento vit/min ${ }^{1}$ & 0,100 & 0,100 & 0,100 & 0,100 \\
\hline Sal comum & 0,354 & 0,354 & 0,354 & 0,354 \\
\hline L-Lisina $\mathrm{HCl}$ & 0,359 & 0,359 & 0,359 & 0,359 \\
\hline DL-Metionina & 0,078 & 0,078 & 0,078 & 0,078 \\
\hline L-Treonina & 0,103 & 0,103 & 0,103 & 0,103 \\
\hline L-Triptofano & 0,018 & 0,018 & 0,018 & 0,018 \\
\hline Ractopamina & 0,000 & 0,025 & 0,050 & 0,100 \\
\hline Caulim (inerte) & 0,100 & 0,075 & 0,050 & 0,000 \\
\hline \multicolumn{5}{|c|}{ Composição nutricional calculada } \\
\hline Proteína bruta, $\mathrm{g} \mathrm{kg}^{-1}$ & 14,09 & 14,09 & 14,09 & 14,09 \\
\hline $\mathrm{EM}, \mathrm{kcal} \mathrm{kg-1}$ & 3.230 & 3.230 & 3.230 & 3.230 \\
\hline $\mathrm{EL}, \mathrm{kcal} \mathrm{kg}^{-1}$ & 2.465 & 2.465 & 2.465 & 2.465 \\
\hline Lisina digestível, $\mathrm{g} \mathrm{kg}^{-1}$ & 0,829 & 0,829 & 0,829 & 0,829 \\
\hline Met+Cist digestível, $\mathrm{g} \mathrm{kg}^{-1}$ & 0,497 & 0,497 & 0,497 & 0,497 \\
\hline Treonina digestível, $\mathrm{g} \mathrm{kg}^{-1}$ & 0,555 & 0,555 & 0,555 & 0,555 \\
\hline Triptofano digestível, $\mathrm{g} \mathrm{kg}^{-1}$ & 0,149 & 0,149 & 0,149 & 0,149 \\
\hline Valina digestível, $\mathrm{g} \mathrm{kg}^{-1}$ & 0,572 & 0,572 & 0,572 & 0,572 \\
\hline Cálcio, $\mathrm{g} \mathrm{kg}^{-1}$ & 0,512 & 0,512 & 0,512 & 0,512 \\
\hline Fósforo disp., $\mathrm{g} \mathrm{kg}^{-1}$ & 0,250 & 0,250 & 0,250 & 0,250 \\
\hline Sódio, $\mathrm{g} \mathrm{kg}^{-1}$ & 0,160 & 0,160 & 0,160 & 0,160 \\
\hline
\end{tabular}

${ }^{1}$ Conteúdo por kg de ração: ferro, 0,1 g; cobre, 0,01 g; cobalto, 0,0002 g; manganês, 0,03 g; zinco, 0,1 g; iodo, 0,001 g; selênio, 0,0003 g; vit. A, 6.000 UI; vit. $\mathrm{D}_{3}, 1.000 \mathrm{UI}$; vit. E, $12 \mathrm{UI}$; vit. $\mathrm{B}_{1}, 0,0005 \mathrm{~g}$; vit. $\mathrm{B}_{2} 0,026 \mathrm{~g}$; vit. $\mathrm{B}_{6} 0,0007 \mathrm{~g}$; ácido pantotênico, $0,01 \mathrm{~g}$; vit. $\mathrm{K}_{3}, 0,0015 \mathrm{~g}$; ácido nicotínico, 0,022 g; vit. $\mathrm{B}_{12}, 0,000015 \mathrm{~g}$; ácido fólico, 0,0002 g; biotina, 0,0005 g; colina, 0,1 g e excipiente q.s.p., $1 \mathrm{~g}$. 
chos castrados, em terminação, alimentados com dietas suplementadas com 5 ppm de ractopamina.

$\mathrm{O}$ peso final dos animais não foi influenciado $(\mathrm{P}>$ $0,10)$ pelos planos de suplementação com ractopamina. Entretanto, comparando-se o desempenho de cada grupo alimentado com dietas suplementadas ao do grupo controle, constatou-se que a suplementação com 5 ppm de ractopamina aumentou $(\mathrm{P}<0,06)$ o peso final, por aumento do ganho de peso diário.

A ractopamina provoca mudanças no metabolismo, alterando a composição do ganho de peso dos animais, ocorrendo maior síntese proteica e bloqueio parcial da lipogênese (Schinckel et al., 2003). A deposição de proteína, por agregar mais moléculas de água que a deposição de gordura (Marinho et al., 2007), justifica o maior ganho de peso dos animais alimentados com dietas suplementadas com 5 ppm de ractopamina.

Os animais alimentados com a dieta controle apresentaram a pior $(\mathrm{P}<0,01)$ conversão alimentar, entre os tratamentos avaliados. Adicionalmente, na comparação da conversão alimentar dos animais do grupo controle às dos demais grupos, observou-se que todos os planos de suplementação melhoraram $(\mathrm{P}<0,04)$ a conversão alimentar. Estes resultados estão de acordo com os relatados por Main et al. (2009), que observaram melhora da conversão alimentar de suínos que receberam dietas suplementadas com 5, 7,5 e 10 ppm de ractopamina.

$\mathrm{O}$ efeito da suplementação das dietas com ractopamina sobre a melhora da conversão alimentar está relacionado com a redução do consumo de ração causado pela ractopamina, sem alteração do ganho de peso dos animais, com exceção dos suplementados com 5 ppm de ractopamina, que apresentaram maior $(\mathrm{P}<0,06)$ ganho de peso e consumo de ração semelhante $(\mathrm{P}>0,10)$, comparados aos do grupo controle.

Considerando-se que não foram realizados ajustes dos níveis aminoacídicos das dietas experimentais, a redução do consumo de ração e, portanto, de nutrientes, observada com a suplementações com níveis superiores a 5 ppm, pode justificar a falta de efeito da ractopamina sobre o ganho de peso diário e sobre o peso final dos animais alimentados com estas dietas. Por este motivo, alguns pesquisadores, como Xiao et al. (1999) e Rostagno et al. (2011), recomendam ajustes dos níveis aminoacídicos de dietas suplementadas com ractopamina que podem chegar a um aumento de até $30 \%$.

Os planos de suplementação com ractopamina não influenciaram $(\mathrm{P}>0,10)$ o peso de carcaça quente (Tabela 3). Não foi observada diferença $(P>0,10)$ entre o peso de carcaça quente dos grupos que receberam as dietas com ractopamina e o do que recebeu a dieta controle. Estes resultados estão de acordo com os relatados por Carr et al. (2005), que não observaram efeito da suplementação com ractopamina sobre o peso de carcaça.

Não foi verificado efeito $(\mathrm{P}>0,10)$ dos planos de suplementação sobre o comprimento de carcaça, assim como não foi observada diferença $(\mathrm{P}>0,10)$ entre $\mathrm{O}$ comprimento de carcaça do grupo controle e os dos demais grupos. Este resultado está de acordo com Almeida et al. (2010) que não observaram influência da suplementação com 5 ppm de ractopamina sobre o comprimento de carcaça de suínos em terminação.

Os animais alimentados com os planos de suplementação gradual apresentaram as menores $(\mathrm{P}<0,03)$

Tabela 2. Desempenho de suínos machos castrados em terminação alimentados com dietas suplementadas com ractopamina

\begin{tabular}{|c|c|c|c|c|c|c|c|c|c|}
\hline $\begin{array}{l}\text { Rac } \\
\text { ppm }\end{array}$ & $\begin{array}{l}\text { PI } \\
\text { kg }\end{array}$ & $\begin{array}{l}\text { PF } \\
\text { kg }\end{array}$ & $\begin{array}{c}\text { CRD } \\
\text { kg }\end{array}$ & $\begin{array}{c}\text { GPD } \\
\text { kg }\end{array}$ & $\mathbf{C A}$ & $\begin{array}{c}\text { CPB } \\
\text { g dia }^{-1}\end{array}$ & $\begin{array}{l}\text { CLis, } \\
\text { g dia }^{-1}\end{array}$ & $\begin{array}{c}\text { CEM } \\
\text { kcal dia }^{-1}\end{array}$ & $\begin{array}{c}\text { CRac } \\
\mathrm{g}\end{array}$ \\
\hline 0 & 68,25 & 94,28 & $2,58 \mathrm{a}$ & 0,87 & $2,97 \mathrm{a}$ & $363,52 \mathrm{a}$ & $21,39 a$ & $8333,40^{\mathrm{a}}$ & $0,00 \mathrm{f}$ \\
\hline 5 & 68,48 & 97,38 & $2,58 \mathrm{a}$ & 0,96 & $2,69 b$ & $363,52 a$ & $21,39 a$ & $8333,40^{\mathrm{a}}$ & $19,35 \mathrm{e}$ \\
\hline 10 & 69,30 & 95,76 & $2,38 \mathrm{ab}$ & 0,88 & $2,70 \mathrm{~b}$ & $335,34 \mathrm{ab}$ & $19,73 \mathrm{ab}$ & $7687,40 \mathrm{ab}$ & $35,73 \mathrm{c}$ \\
\hline 20 & 68,48 & 94,57 & $2,19 b$ & 0,87 & $2,52 b$ & $308,57 b$ & $18,16 \mathrm{~b}$ & $7073,70 b$ & $70,10^{\mathrm{a}}$ \\
\hline $5-10$ & 68,60 & 94,26 & $2,35 \mathrm{ab}$ & 0,86 & $2,73 b$ & $331,12 \mathrm{ab}$ & $19,48 \mathrm{ab}$ & $7590,50 \mathrm{ab}$ & $26,40 \mathrm{~d}$ \\
\hline $10-20$ & 68,56 & 94,70 & $2,29 a b$ & 0,87 & $2,63 b$ & $322,66 a b$ & $18,98 \mathrm{ab}$ & $7396,70 \mathrm{ab}$ & $51,53 b$ \\
\hline Valor P & - & 0,218 & 0,027 & 0,256 & 0,005 & 0,027 & 0,003 & 0,003 & 0,001 \\
\hline \multicolumn{10}{|c|}{ Probabilidade para os contrastes } \\
\hline $0 \times 5$ & - & 0,053 & 0,941 & 0,054 & 0,005 & 0,941 & 0,941 & 0,940 & 0,001 \\
\hline $0 \times 10$ & - & 0,762 & 0,063 & 0,778 & 0,031 & 0,063 & 0,063 & 0,063 & 0,001 \\
\hline $0 \times 20$ & - & 0,843 & 0,071 & 0,855 & 0,007 & 0,070 & 0,070 & 0,070 & 0,001 \\
\hline $0 \times 5-10$ & - & 0,963 & 0,025 & 0,939 & 0,004 & 0,026 & 0,026 & 0,026 & 0,001 \\
\hline $0 \times 10-20$ & - & 0,986 & 0,004 & 0,889 & 0,001 & 0,004 & 0,004 & 0,004 & 0,001 \\
\hline $\mathrm{CV}(\%)$ & - & 2,540 & 9,190 & 9,070 & 6,890 & 9,230 & 9,230 & 9,230 & 16,280 \\
\hline
\end{tabular}

Rac: ractopamina; PI: peso inicial; PF: peso final; CRD: consumo de ração diário; GPD: ganho de peso diário; CA: conversão alimentar; CPB: consumo de proteína bruta; CLis: consumo de lisina digestível; CEM: consumo de energia metabolizável; CRac: consumo total de ractopamina.

a,b Médias seguidas por letras distintas, nas colunas, diferem $(\mathrm{P}<0,10)$ pelo teste SNK. 
espessuras de toucinho, enquanto os que não receberam o aditivo apresentaram os maiores valores para esta variável. Porém, ao serem comparadas as espessuras de toucinho dos animais alimentados com dietas suplementadas com as dos que consumiram a dieta controle, observou-se que a inclusão de ractopamina reduziu $(\mathrm{P}<0,10)$ a espessura de toucinho. Em estudo semelhante, See et al. (2004) observaram redução da espessura de toucinho de suínos alimentados com dietas suplementadas com ractopamina, tanto com a suplementação com níveis constantes quanto com a suplementação gradual.

Os maiores $(\mathrm{P}<0,01)$ valores observados para a profundidade de músculo foram apresentados pelos animais alimentados com a dieta suplementada com 5 ppm de ractopamina, enquanto os animais do tratamento controle apresentaram as menores profundidades de músculo. Ainda assim, comparando-se a profundidade de músculo de cada grupo suplementado com ractopamina com a do grupo controle, observou-se que a ractopamina aumentou $(\mathrm{P}<0,09)$ a profundidade de músculo em todos os níveis de suplementação. Marinho et al. (2007) avaliaram dietas suplementadas com 5 ppm de ractopamina para suínos em terminação e constataram que o aditivo aumentou a profundidade de músculo.

A carcaça dos animais alimentados com a dieta controle apresentou o menor $(\mathrm{P}<0,01)$ percentual de carne magra. Na comparação de cada um dos grupos alimentados com dietas suplementadas com o grupo controle, observou-se que os animais alimentados com as dietas suplementadas apresentaram carcaças com maiores ( $\mathrm{P}$ $<0,06)$ percentuais de carne magra. See et al. (2004) observaram aumento do percentual de carne magra da carcaça com as suplementações constante e gradual.

$\mathrm{O}$ grupo alimentado com $5 \mathrm{ppm}$ de ractopamina na dieta apresentou a maior $(\mathrm{P}<0,02)$ quantidade de carne magra da carcaça, enquanto o grupo controle apresentou o menor valor para esta variável. Contudo, na comparação de cada grupo alimentado com ractopamina com o grupo controle, observou-se aumento $(\mathrm{P}<0,06)$ da quantidade de carne magra da carcaça, em todos os planos de suplementação. O aumento da quantidade de carne magra, em resposta à suplementação de ractopamina, está de acordo com as observações de Marinho et al. (2007) que constataram maiores taxas de deposição de carne magra na carcaça de suínos, alimentados com 5 ppm de ractopamina.

Os efeitos positivos da suplementação com ractopamina sobre as características de carcaça estão relacionados com a redução da síntese de ácidos graxos no tecido adiposo e com o aumento da síntese proteica do músculo (Schinckel et al., 2003).

$\mathrm{O}$ menor $(\mathrm{P}<0,02)$ índice de bonificação foi observado para a carcaça dos animais alimentados com a dieta controle. Na comparação entre cada grupo alimentado com dietas suplementadas e o grupo controle, observouse aumento $(\mathrm{P}<0,01)$ do índice de bonificação, em todos os planos de suplementação com ractopamina.

Apesar de não terem sido realizados os ajustes aminoacídicos, a utilização da ractopamina promoveu melhoras desejáveis das características de carcaça dos animais, resultado que indica a possibilidade de suplementação com 5 ppm de ractopamina sem a correção aminoacídica.

Tabela 3. Características de carcaça de suínos machos castrados em terminação alimentados com dietas suplementadas com ractopamina

\begin{tabular}{|c|c|c|c|c|c|c|c|}
\hline $\begin{array}{l}\text { Rac } \\
\text { ppm }\end{array}$ & $\begin{array}{c}\text { PCQ } \\
\mathrm{kg}\end{array}$ & $\begin{array}{l}\mathrm{CC} \\
\mathrm{cm}\end{array}$ & $\begin{array}{l}\text { ET } \\
\text { mm }\end{array}$ & $\begin{array}{l}\mathbf{P M} \\
\mathbf{m m}\end{array}$ & $\begin{array}{c}\text { CM } \\
\%\end{array}$ & $\begin{array}{c}\text { CM } \\
\text { kg }\end{array}$ & IB \\
\hline 0 & 69,80 & 92,17 & $12,52 \mathrm{a}$ & $60,09 \mathrm{c}$ & $58,75 b$ & $41,01 \mathrm{~b}$ & $102,31 \mathrm{~b}$ \\
\hline 5 & 72,74 & 91,57 & $11,96 a b$ & $67,94 a$ & $59,86 a$ & $43,54 \mathrm{a}$ & $104,26 \mathrm{a}$ \\
\hline 10 & 69,81 & 92,71 & $10,52 \mathrm{ab}$ & $66,29 \mathrm{ab}$ & $60,53 a$ & $42,26 a b$ & $104,09 \mathrm{a}$ \\
\hline 20 & 70,75 & 92,29 & $10,90 \mathrm{ab}$ & $66,83 \mathrm{ab}$ & $60,36 \mathrm{a}$ & $42,70 \mathrm{ab}$ & $104,20 \mathrm{a}$ \\
\hline $5-10$ & 69,73 & 93,00 & $9,92 b$ & $63,62 b$ & $60,61 \mathrm{a}$ & $42,26 \mathrm{ab}$ & $104,15 \mathrm{a}$ \\
\hline $10-20$ & 69,60 & 91,50 & $9,86 b$ & $66,15 \mathrm{ab}$ & $60,90 \mathrm{a}$ & $42,39 \mathrm{ab}$ & $104,41 \mathrm{a}$ \\
\hline Valor P & 0,192 & 0,700 & 0,030 & 0,001 & 0,002 & 0,013 & 0,019 \\
\hline \multicolumn{8}{|c|}{ Probabilidade para os contrastes } \\
\hline $0 \times 5$ & 0,597 & 0,472 & 0,008 & 0,083 & 0,001 & 0,059 & 0,001 \\
\hline $0 x 10$ & 0,111 & 0,588 & 0,074 & 0,001 & 0,055 & 0,001 & 0,001 \\
\hline $0 \times 20$ & 0,559 & 0,640 & 0,041 & 0,001 & 0,002 & 0,054 & 0,001 \\
\hline $0 \times 5-10$ & 0,893 & 0,567 & 0,008 & 0,001 & 0,001 & 0,041 & 0,001 \\
\hline $0 \times 10-20$ & 0,219 & 0,929 & 0,096 & 0,001 & 0,005 & 0,018 & 0,001 \\
\hline $\mathrm{CV}(\%)$ & 5,170 & 3,080 & 21,750 & 6,290 & 2,200 & 5,410 & 19,500 \\
\hline
\end{tabular}

Rac: ractopamina; PCQ: peso de carcaça quente; ET: espessura de toucinho; CC: comprimento de carcaça; PM: profundidade de músculo; CM: carne magra; IB: índice de bonificação de carcaças.

${ }^{\mathrm{a}, \mathrm{b}}$ Médias seguidas por letras distintas, nas colunas, diferem $(\mathrm{P}<0,10)$ pelo teste SNK. 


\section{CONCLUSÕES}

A suplementação de 5 ppm de ractopamina em dietas sem ajustes aminoacídicos melhora o desempenho e as características de carcaça de suínos em terminação, nos 30 dias pré-abate.

\section{REFERÊNCIAS}

Almeida VV, Berenchtein B, Costa LB, Tse MLP, Braz DB \& Miyada VS (2010) Ractopamina, cromo-metionina e suas combinações como aditivos modificadores do metabolismo de suínos em crescimento e terminação. Revista Brasileira de Zootecnina, 39:19691977.

Armstrong TA, Kremer BT, Marsteller TA \& Mechler D (2005) Effects of ractopamine step-up use programs on finishing pigs fed under commercial conditions. Journal of Swine Health and Production, 13:66-71.

Bridi AM \& Silva CA (2007) Métodos de avaliação de carcaça e da carne suína. Londrina, Midiograf. 97p.

Carr SN, Rincker PJ, Killefer J, Baker DH, Ellis M \& Mckeith FK (2005) Effects of different cereal grains and ractopamine hydrochloride on performance, carcass characteristics, and fat quality in late-finishing pigs. Journal of Animal Science, 83:223230.

Crome PK, McKeith FK, Carr TR, Jones DJ, Mowrey DH \& Cannon JE (1996) Effect of ractopamine on growth performance, carcass composition, and cutting yields of pigs slaughtered at 107 and 125 kilograms. Journal of Animal Science, 74:709-716.

Guidoni AL (2000) Melhoria de processos para a tipificação e valorização de carcaças suínas no Brasil. In: Conferência Internacional Virtual Sobre Qualidade de Carne Suína, Concórdia. Anais eletrônicos, EMBRAPA/CNPSA. Disponível em: <http://www.cnpsa.embrapa.br/ sgc/sgc_publicacoes/anais00cv_guidoni_pt.pdf> Acessado em: 05 de outubro de 2012.

Main RG, Dritz SS, Tokach MD, Goodband RD, Nelssen JL \& Derouchey JM (2009) Effects of ractopamina $\mathrm{HCl}$ dose and treatment period on pig performance in a commercial finishing facility. Journal of Swine Health and Production, 17:134-139.

Marinho PC, Fontes DO, Silva FCO, Silva MA, Pereira FA \& Arouca CLC (2007) Efeito da ractopamina e de métodos de formulação de dietas sobre o desempenho e as características de carcaça de suínos machos castrados em terminação. Revista Brasileira de Zootecnia, 36:1061-1068.

Mills SE (2002) Implications of feedback regulation of beta-adrenergic signaling. Journal of Animal Science, 80:30-35.

Rostagno HS, Albino LFT, Donzele JL, Gomes PC, Oliveira RF, Lopes DC, Ferreira AS, Barreto SLT \& Euclides RF (2011) Tabelas brasileiras para aves e suínos: composição de alimentos e exigências nutricionais. $3^{\mathrm{a}}$ ed. Viçosa, UFV. 252p.

Sampaio CAP, Cristani J, Dubiela JÁ, Boff CE \& Oliveira MC (2004) Avaliação do ambiente térmico em instalações para crescimento e terminação de suínos utilizando os índices de conforto térmico nas condições tropicais. Ciência Rural, 34:785-790.

Schinckel AP, Li N, Richert BT, Preckel PV \& Einstein ME (2003) Development of a model to describe the compositional growth and dietary lysine requirements of pig fed ractopamine. Journal of Animal Science, 81:1106-1119.

See MT, Armstrong TA \& Weldon WC (2004) Effect of a ractopamine feeding program on growth performance and carcass composition in finishing pigs. Journal of Animal Science, 82:2474-2480.
Webster MJ, Goodband RD, Tokach MD, Nelssen JL, Dritz SS, Unruh JA, Brown KR, Real DE, Derouchey JM, Woodworth JC, Groesbeck CN \& Marsteller TA (2007) Interactive effects between ractopamine hydrochloride and dietary lysine on finishing pig growth performance, carcass characteristics, pork quality and tissue accretion. The Professional Animal Scientist, 23:597-611.

Xiao RJ, Xu ZR \& Chen HL (1999). Effects of ractopamine at different dietary protein levels on growth performance and carcass characteristics in finishing pigs. Animal Feed Science and Technology, 79:119-127. 